\title{
Biologia floral e sistema reprodutivo de Byrsonima coccolobifolia (Kunth) em uma savana amazônica
}

\author{
Rosa M $^{\text {a Cordovil BENEZAR }}{ }^{1}$, Luiz Alberto PESSONI ${ }^{1}$
}

\section{RESUMO}

(Biologia floral e sistema reprodutivo de Byrsonima coccolobifolia Kunth em uma savana amazônica). A biologia reprodutiva de Byrsonima coccolobifolia, foi avaliada em uma população de savana do Estado de Roraima. A espécie é constituída de arbustos e arvoretas com altura inferior a $3 \mathrm{~m}$, de flores hermafroditas zigomorfas, pentâmeras, reunidas em inflorescências do tipo racemo terminal, produzidos em brotações novas, o cálice é composto por cinco sépalas, que apresentam um par de glândulas produtoras de óleo. A corola é formada por cinco pétalas albo-róseas e unguiculadas, o androceu é composto por dez estames com anteras de coloração amarela. A antese pode ser noturna ou diurna, estende-se por um período médio de 12 horas e as flores costumam ficar abertas e vistosas por um período adicional de 15 horas, quando se inicia a senescência. Foram registrados dois episódios de floração e o fogo parece ser um fator ambiental estimulador desta fenofase. Os visitantes florais predominantes foram abelhas das famílias Anthophoridae (Centris sp. e Xylocopa sp.) e Apidae (Apis mellifera e Bombus sp.). Os resultados das polinizaçóes controladas e o cálculo do índice de auto-incompatibilidade (ISI) indicam que a espécie apresenta comportamento protogínico e é autocompatível, produzindo frutos em todos os tratamentos de autopolinização em proporçôes semelhantes à polinização natural, não sendo confirmada a produção de frutos apomíticos. Entretanto, os percentuais de frutos formados nos tratamentos de xenogamia foram significativamente superiores aos tratamentos de autofertilização, indicando que B. coccolobifolia apresenta um sistema reprodutivo misto com níveis elevados de alogamia e autogamia.

\section{PALAVRAS-CHAVE}

Byrsonima, murici, biologia floral, sistema reprodutivo.

\section{Floral Biology and the reproductive system of Byrsonima coccolobifolia (Kunth) in an amazonian savanna}

\begin{abstract}
(Floral biology and the reproductive system of Byrsonima coccolobifolia Kunth in an amazonian savanna). The reproductive biology of Byrsonima coccolobifolia was evaluated in a savanna area of State of Roraima, Brazil. This is a woody species of bushes and small trees $3 m$ tall. The flowers are hermaphrodite, pentamerous, zygomorphic, arranged in a terminal inflorescence, produced in new sprouts. Five sepals form the calyx, each one with a pair of oil-producing glands, called elaiophores. The corolla is pale-pink and formed by five clawed and fringed petals, and the androecium is composed of ten stamens with yellow-colored anthers. The anthesis can be nocturnal or diurnal, which lasts for an average of 12 hours, and the flowers usually remain open and pretty for 15 more hours after the end of the process, when senescing begins. Two flowering periods were registered and the fire seems to be a factor environmental stimulator of this phonological phase. The predominant floral visitors were bees of the families Anthophoridae (Centris sp. and Xylocopa sp.) and Apidae (Apis mellifera and Bombus sp.). Results of controlled pollination and the self-incompatibility index (ISI) suggest that the species presents protogynous behavior and is self-compatible, producing fruits in all self-pollination treatments in similar proportions as under natural pollination. The production of apomict fruits was not confirmed. However, the percentages of fruits formed under xenogamy treatments were significantly superior to the fruit-set in self-fertilization. This suggests that the species presents a mixed reproductive system with high allogamy and autogamy levels.
\end{abstract}

\section{KEY WORDS}

Byrsonima, murici, floral biology, reproductive system. 


\section{INTRODUÇÃO}

O interesse pela biologia reprodutiva das plantas tropicais tem sido crescente, resultando em um grande número de publicações nos últimos anos. Alguns estudos mais abrangentes e importantes revisões sobre o tema são encontrados em Zapata \& Arroyo (1978); Faegri \& Pijl van der (1976); Bullock (1985); Newstrom et al. (1994); Oliveira (1998); Oliveira \& Gibbs (2000) e Gribel (2001). Um panorama do status atual do conhecimento e da importância deste tipo de trabalho para o uso, manejo e conservação dos recursos naturais da Amazônia é apresentado por Gribel (2001).

A família Malpighiaceae compreende cerca de 63 gêneros e 1.100 espécies, sendo composta de árvores, arbustos e lianas, de ampla ocorrência nas regiōes tropicais (Vogel, 1990; Barroso, 1991). O gênero Byrsonima, cujas espécies são conhecidas popularmente como murici, está distribuído nos campos cerrados e savanas neotropicais (Cavalcante, 1991; Miranda \& Absy, 1997). Cavalcante (1991) registra que muitas espécies são encontradas na Amazônia, sugerindo que esse gênero tenha aí o seu centro de origem e dispersão.

Byrsonima coccolobifolia Kunth, é freqüente nas áreas de vegetação aberta da América do Sul, havendo registros de sua ocorrência para o Brasil, Bolívia, Venezuela e República Cooperativa da Guiana (Missouri Botanical Garden, 2002). Na Amazônia, esta espécie ocorre em áreas de mata, cerradão e cerrado aberto (Pott \& Pott, 1994), constituindo-se numa das cinco principais espécies lenhosas do ambiente de savana no Estado de Roraima (Miranda, 1998).

No Cerrado do Brasil Central, o período de floração de $B$. coccolobifolia tem duração de dois meses, aproximadamente, com início nos meses de setembro ou outubro e final nos meses de novembro ou dezembro (Barros, 1992). No Pantanal a floração também se concentra no período de outubro a dezembro, com frutificação na estação das chuvas (Pott \& Pott, 1994).

Em Roraima, os frutos de B. coccolobifolia são explorados de maneira extrativista por populaçôes tradicionais (indígenas e não indígenas), para serem empregados no preparo de sucos e refrescos. Regionalmente esta espécie é denominada de 'murici' e ocorre associada a B. crassifolia $\mathrm{L}$., que é sempre mais abundante, porém apresenta frutos menores e é designada de 'mirixi'. A planta também é utilizada como forrageira, em épocas de falta de pasto, como ornamental, na confecção de móveis e na produção de lenha e carvão (Pott \& Pott, 1994). Algumas de suas propriedades medicinais foram avaliadas por Alves et al. (2000), que comprovaram atividade moluscocida contra Biomphalaria glabrata, e bactericida para Staphylococcus aureus, Bacillus cereus e Pseudomonas aeruginosa.

Entre os trabalhos abordando a biologia reprodutiva de espécies do gênero Byrsonima no Brasil destacam-se os realizados por Rêgo \& Albuquerque (1989) e Pereira (2001), para $B$. crassifolia; Silva (1990) e Teixeira \& Machado (2000), para $B$. sericea; Barros (1992), Bergamin (1998) e Oliveira \& Gibbs (2000) que realizaram observaçōes para as espécies B. coccolobifolia e B. verbascifolia. O trabalho de Barros (1992) abrange ainda outras cinco espécies deste gênero.

O presente trabalho descreve a biologia reprodutiva de Byrsonima coccolobifolia, em um ambiente de savana amazônica, quanto aos seguintes aspectos: descrição da morfologia floral, acompanhamento dos eventos de antese e senescência, registro dos insetos visitantes mais freqüentes no período de floração e frutificação e determinação do sistema reprodutivo da espécie.

\section{MATERIAL E MÉTODOS}

As observações de campo foram realizadas no Centro de Ciências Agrárias da Universidade Federal de Roraima, município de Boa Vista (0251'50"N, 6042’54"W). A área, com cerca de 400 ha, é utilizada como pasto natural para atividades de pecuária extensiva e é coberta por savana arbórea aberta (campo sujo), descrita por Miranda (1998) como o tipo predominante de savana em Roraima. No Estado, este tipo de formação se caracteriza pela presença de árvores baixas $(5 \mathrm{a} 7 \mathrm{~m})$, espaçadas e de aspecto xeromórfico, associadas com um tapete graminoso contínuo dominado por espécies de Andropogon e Trachypogon (Veloso et al., 1975). As espécies lenhosas mais freqüentes do local são Byrsonima crassifolia L., Byrsonima coccolobifolia Kunth, Curatella americana L. e Bowdichia virgilioides Kunth.

O clima predominante na região é o tropical sazonal - Aw, na classificação de Köppen, com nítida estação seca e precipitação média anual é de $1.614 \mathrm{~mm} / \mathrm{ano}$, sendo que a maior concentração das chuvas (58\%) ocorre entre os meses de maio e julho e a menor (9\%), entre os meses de dezembro e março (Barbosa, 1997). As médias anuais de temperatura e umidade relativa são, respectivamente, $27,4^{\circ} \mathrm{C}$ e $76 \%$, (EMBRAPA, 1982).

Os experimentos foram realizados entre os meses de dezembro de 2000 e abril de 2001, totalizando, aproximadamente, 370 horas de observações de campo e abrangendo 13 plantas de $B$. coccolobifolia. Foi coletado material botânico de todos os indivíduos para confirmação taxonômica, realizada no Herbário do INPA, e os testemunhos foram depositados no herbário da UFRR ( ${ }^{\circ}$ de registro -1.550 a 1.563 ). A caracterização morfométrica das folhas, inflorescências e verticilos florais foram realizada em material fresco, coletado de cinco indivíduos.

Durante o período de estudo a área foi atingida por um incêndio no início do mês de fevereiro 2001. Esse fato provocou a combustão quase completa do estrato herbáceo do local e queda da maior parte das folhas das plantas lenhosas. Logo em seguida, porém, ocorreu um novo episódio de floração de B. coccolobifolia, de maior intensidade e abrangência que o observado anteriormente. Assim, as observaçôes foram realizadas em dois eventos de florescimento distintos: antes e depois do fogo. 
O primeiro período de observação referente à biologia floral ocorreu entre os meses de dezembro de 2000 e janeiro de 2001. O processo de antese foi acompanhado a partir da observação contínua de botões florais marcados em pré-antese. Foram registradas as alteraçôes relativas à cor, posições dos verticilos florais, dos órgãos reprodutivos e a presença de insetos visitantes. Foi anotado também o tempo de duração das flores e o número médio de flores abertas por inflorescência.

A emissão de odor foi investigada através do olfato em campo e também em laboratório. Para a verificação no laboratório, as inflorescências com botôes florais já desenvolvidos e flores recémabertas, foram coletadas e reservadas em recipientes de vidro lacrados, previamente preparados com algodão umedecido no fundo. A produção de odor nestas flores foi verificada em intervalos de cinco horas, por 48 horas (Teixeira \& Machado, 2000). A eventual presença de substâncias como óleo ou néctar foram observadas com uma lupa manual.

Quanto aos visitantes florais, foram realizadas observações adicionais em horários variados do dia, durante todo o pico de floração, que durou cerca de 30 dias. Foram observados o comportamento, o tempo de permanência na flor e, ainda, o horário de maior concentração das visitas, procedendo-se a coleta de alguns exemplares com auxílio de rede entomológica. Os insetos coletados foram asfixiados e preservados a seco, separados por ordem e/ou família e morfotipos. Posteriormente, exemplares de cada morfotipo foram enviados à Dra J.D. Ribeiro (INPAManaus) para identificação taxonômica.

O segundo período de observação da biologia floral ocorreu entre março e abril de 2001, iniciando-se, aproximadamente, um mês após a área ter sido atingida pelo fogo. As observaçôes restringiram-se ao acompanhamento da antese de um grupo de botóes florais previamente marcados e ao registro e coleta dos visitantes florais, por um período adicional de 30 dias, durante o pico de floração.

A determinação do sistema reprodutivo foi realizada em dois experimentos, conduzidos paralelamente às observaçōes da antese e dos visitantes florais. No primeiro experimento, poucos indivíduos se encontravam em flor e a maioria destes apresentavam poucos racemos por isso, foram escolhidos seis indivíduos com maior quantidade de racemos.

Cinco dos maiores racemos foram marcados com cordōes de cores diferentes e, quatro deles, isolados no estádio de "botão floral" com sacos de papel semi-permeável (Teixeira \& Machado, 2000), sendo cada um submetido a um dos seguintes tratamentos: xenogamia sem emasculação (as peças florais dos botōes receptores, em pré-antese, foram abertas com pinça de ponta fina e a polinização foi realizada esfregando-se sobre o estigma receptor as anteras da flor recém-aberta da planta doadora); xenogamia com emasculação (procedimentos semelhantes ao tratamento anterior, com a diferença de que se retirou as anteras do botão receptor antes de se realizar a polinização); geitonogamia (as peças florais dos botōes receptores, em pré-antese, foram abertas com pinça de ponta fina e a polinização foi feita esfregando-se sobre o estigma receptor de uma flor recém-aberta da mesma planta, também isolada desde o estádio de botão floral); autopolinização espontânea (as inflorescências foram apenas mantidas isoladas com saco de papel semi-permeável até abertura de todos os botôes florais). Os racemos não isolados foram utilizados para a avaliação da polinização natural (as inflorescências foram apenas marcadas com o cordão de cor correspondente ao tratamento, permanecendo expostas aos visitantes florais). Observaçóes adicionais da polinização natural foram realizadas em cinco inflorescências marcadas em uma sétima planta.

A receptividade do estigma, no estádio de pré-antese, foi estabelecida a partir de informaçoes da literatura (Barros, 1992; Teixeira \& Machado, 2000) mas, principalmente, a partir de ensaios preliminares de polinização, conduzidos em indivíduos da população estudada. O mecanismo de isolamento foi mantido até a abertura de todas as flores do racemo e início do desenvolvimento dos frutos, ou murchamento e abscisão das peças florais.

No segundo experimento foram utilizados cinco indivíduos, repetindo-se os tratamentos aplicados no primeiro, com exceção da xenogamia sem emasculação, sendo acrescentados, porém, a avaliação da apomixia (I - com eliminação das anteras e do estigma, II - com eliminação apenas das anteras); autopolinização induzida (o estigma da flor recém-aberta naturalmente recebeu pólen das anteras da própria flor: I - tratamento aplicado seqüencialmente em várias flores de uma mesma inflorescência, isolada desde a pré-antese; II - procedimentos semelhantes ao tratamento anterior, diferindo por ser aplicado apenas nas flores abertas num mesmo dia na inflorescência, com eliminação dos demais botôes florais).

Todos os tratamentos de polinização manual foram feitos diariamente e os resultados foram comparados através do teste do qui-quadrado $(\mathrm{p}=0,05)$, considerando-se o números de flores tratadas versus números de frutos formados.

O "índice de auto-incompatibilidade" (ISI) e a "eficiência reprodutiva” (RE) estabelecidos por Zapata \& Arroyo (1978), foram calculados com as modificaçōes apresentadas por Oliveira \& Gibbs (2000) e Freitas \& Oliveira (2002). O ISI foi obtido pela divisão do percentual de frutificaçōes resultantes de autopolinizaçôes pelo percentual de frutos formados por xenogamia manual e a RE pela divisão do percentual de frutificaçōes provenientes de polinização natural pelo percentual de frutificações por xenogamia.

\section{RESULTADOS E DISCUSSÃO}

\section{HÁBITO E MORFOLOGIA FLORAL}

Os indivíduos de Byrsonima coccolobifolia observados são arvoretas e arbustos com altura média de 2,78m. Apresentam 
folhas obovadas de filotaxia oposta cruzada, que medem cerca de $10,1 \mathrm{~cm}$ de comprimento e $6,5 \mathrm{~cm}$ de largura $(\mathrm{n}=160)$. Possuem inflorescência terminal do tipo racemo, com média de 13,3 \pm $1,8 \mathrm{~cm}$ de comprimento ( $\mathrm{n}=40$ ) e $27,2 \pm 6,4$ botôes florais por racemo $(n=40)$. As informaçôes referentes ao porte da planta condizem com os relatos feitos por Miranda (1998) de que, nas savanas de Roraima, esta espécie dificilmente atinge três metros de altura. Barros (1992) encontrou valores entre 1 e 3,8 m de altura, para indivíduos da espécie ocorrentes em uma área de cerrado do Distrito Federal, enquanto outras espécies do gênero, de ocorrência simpátrica, apresentaram desde porte subarbustivo ( 0,2 a $0,5 \mathrm{~m})$ até porte arbóreo ( 4 a $5 \mathrm{~m})$. Indivíduos de $B$. sericea, estudada por Teixeira \& Machado (2000) na Zona da Mata de Pernambuco, podem atingir uma altura de $20 \mathrm{~m}$. Byrsonima coccolobifolia diferencia-se também quanto ao tamanho dos racemos, sendo esses mais longos e com menor número de botôes florais do que os relatados por Teixeira \& Machado (2000), para B. sericea.

As flores são hermafroditas, zigomorfas e pêntameras. As sépalas possuem, em média, $3 \mathrm{~mm}$ de comprimento e $2 \mathrm{~mm}$ de largura, coloração verde, nos botôes florais jovens e levemente amarelada, nos botóes totalmente desenvolvidos. Na base de cada sépala existe um par de glândulas, os elaióforos, que produzem óleo liberado continuamente, desde a pré-antese até a abertura completa da flor. A partir do segundo dia após a antese, a quantidade de óleo liberada é aparentemente reduzida.

A corola é composta por pétalas unguiculadas, de coloração rósea intensa nos botôes florais. Tal cor vai se perdendo à medida que o botão se desenvolve totalmente e se aproxima da antese. $\mathrm{Na}$ flor aberta, as pétalas são albo-róseas, com $7 \mathrm{~mm}$ de comprimento e $4 \mathrm{~mm}$ de largura, em média. Nota-se que quatro pétalas são semelhantes e uma delas é diferenciada em forma de estandarte, pois é superior, menor e distende-se totalmente em relação às demais, que são côncavas (Fig. 1). $\mathrm{O}$ androceu é constituído por dez estames com anteras de deiscência longitudinal. Os estames que se localizam na base da pétala em forma de estandarte são menores que os demais. O gineceu é constituído por ovário súpero, tricarpelar, trilocular, com três estiletes persistentes, livres entre si, de ápice agudo, posicionados na altura dos ápices das anteras ou apresentam leve projeção para além deste limite, na flor completamente aberta (Fig. 1).

A base do pedúnculo do botão floral é protegida por três brácteas com ápice agudo, sendo que uma das brácteas é visivelmente maior que as demais.

Os frutos são drupáceos. Quando maduros, o pericarpo apresenta coloração alaranjada, de consistência macia e suculenta, enquanto o endocarpo é muito rígido. Tanto verdes quanto maduros são muito predados, superficialmente ou de forma mais profunda, resultando na exposição do endocarpo.

Todas as características florais relatadas anteriormente são semelhantes ao descrito por Barros (1992), para os indivíduos de B. coccolobifolia do cerrado do Distrito Federal, bem como para outras espécies do gênero de ocorrência simpátrica, com exceção da cor da corola, que é predominantemente amarela. Teixeira \& Machado (2000), ao avaliarem a morfologia floral de B. sericea, destacam também que alguns indivíduos da população apresentam flores sem elaióforos. Por outro lado, todos indivíduos de B. coccolobifolia observados no presente trabalho apresentam flores com elaióforos. De acordo com Vogel (1990), a ausência de elaióforos em parte dos indivíduos de uma mesma população é uma característica comum em espécies do gênero Byrsonima, caracterizado uma condição apomórfica das Malpighiaceae do Novo Mundo. Tal condição, segundo o autor, resultaria em economia de recursos, pela redução nas recompensas florais ao polinizador, com manutenção dos níveis de polinização através de uma estratégia de mimetismo entre indivíduos com e sem elaióforos.

\section{BIOLOGIA FLORAL}

A antese teve duração de onze a doze horas, iniciando-se, no primeiro período de observação, por volta das 16 horas e terminando na madrugada do dia seguinte. Após a queimada, foi observado o processo se iniciando em horários variados do dia, mas com o mesmo tempo de duração. Foi registrado um total de até seis flores em antese por racemo, não sendo percebido pelo olfato, a liberação de qualquer tipo de odor. Barros (1992), por outro lado, registrou antese apenas no período diurno (entre 6:00 e 16:00h) para sete espécies de Byrsonima, entre elas, $B$. coccolobifolia. Antese diurna, com início em diferentes horários do dia, e ausência de odor também são características das flores de B. sericea (Teixeira \& Machado, 2000).

O processo de antese inicia-se quando os botôes apresentamse bastante desenvolvidos, o ápice das sépalas desprendem-se das pétalas e começam a enrolar-se de forma contrária à sua inserção. Devido ao enrolamento das sépalas, estas acabam deixando entre si, pequenos espaços onde as bases flexíveis das pétalas serão "encaixadas", com exceção da pétala mais interna em forma de estandarte. Embora sua base também fique entre as sépalas, a mesma não relaxa totalmente como as outras e acaba ficando ereta (Fig. 1).

Esse processo de abertura deixa totalmente expostos os estigmas e estames. A coloração albo-rósea das pétalas faz destacar a cor amarela das anteras que, na flor recém-aberta, encontram-se centralizadas junto ao gineceu. Essa posição começa a mudar algumas horas depois, com os primeiros raios solares (para flores com antese iniciada no final da tarde do dia anterior), pois os estames afastam-se um pouco do centro da flor. Os estiletes também se afastam, indo de encontro aos estames, a ponto dos estigmas tocarem a abertura longitudinal das anteras, permanecendo assim até o início da tarde, quando retornam novamente ao centro.

As flores ficam abertas e vistosas por um período aproximado de 15 horas, a contar do final do processo de distensão das 


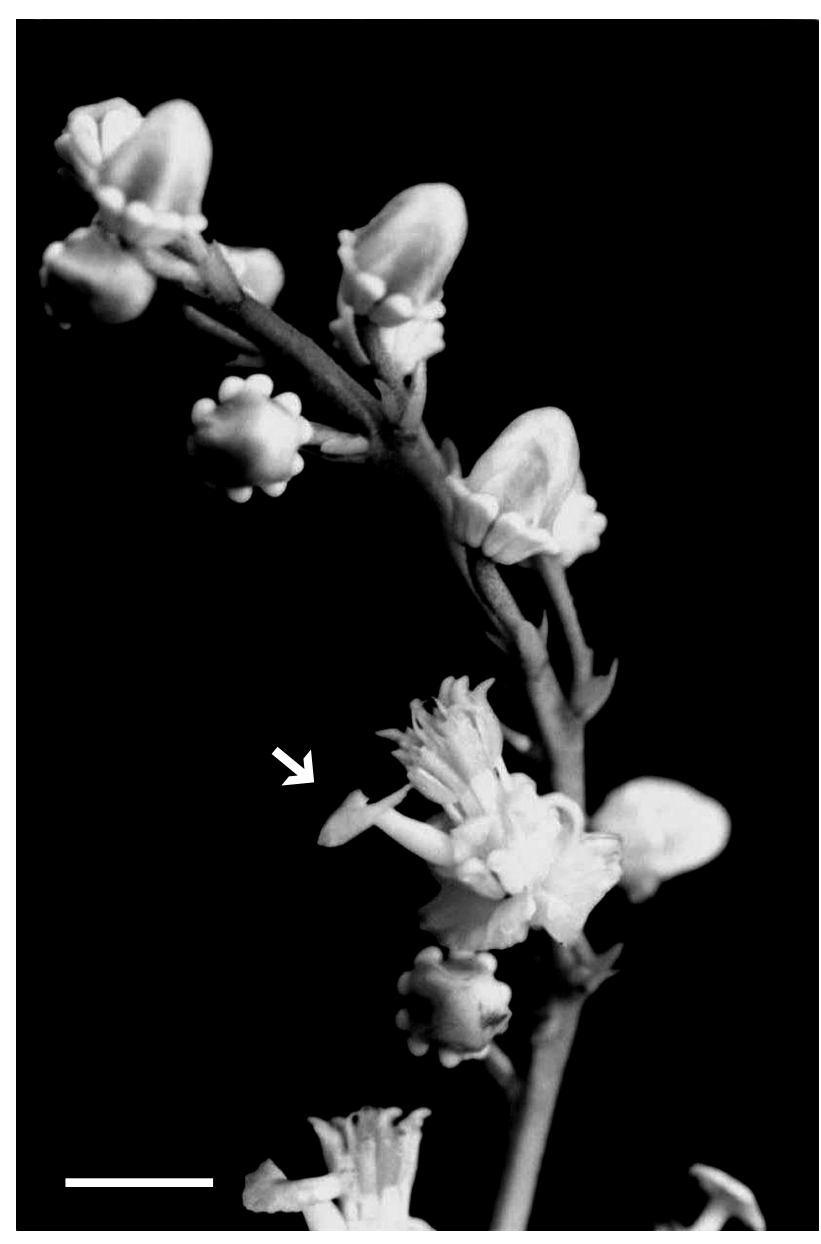

Figura 1 - racemo de B. coccolobifolia destacando a posição ereta da pétala em forma de estandarte, na flor recém aberta; notar também a disposição das anteras e estigmas nesta fase. Fotos: J.F. Luz

pétalas e sépalas, quando se inicia o processo de senescência, percebido pela mudança de coloração tanto da corola quanto dos estiletes, seguido pela queda progressiva das pétalas num intervalo de dois a três dias. Independentemente da ocorrência de fecundação, as sépalas levam até cinco dias, a contar do início da antese, para que seus ápices retornem à posição inicial, fechandose em torno do eixo floral, disposição que protege o ovário (Fig. 2). Se não ocorrer a fecundação, ocorrerá a abscisão na base do receptáculo de todas as estruturas florais restantes, se ocorrer fecundação as sépalas persistirão mesmo depois do desenvolvimento do fruto.

Embora não tenha sido realizado nenhum teste, bioquímico e/ou histoquímico, para determinar a duração total do período de receptividade dos estigmas, presumiu-se que ela se estenda até o início do processo de senescência da flor, conforme relatado por Barros (1992). Neste caso, o movimento retardado apresentado por estas estruturas em direção às anteras, poderia se constituir em uma estratégia que facilitaria o processo de autogamia,

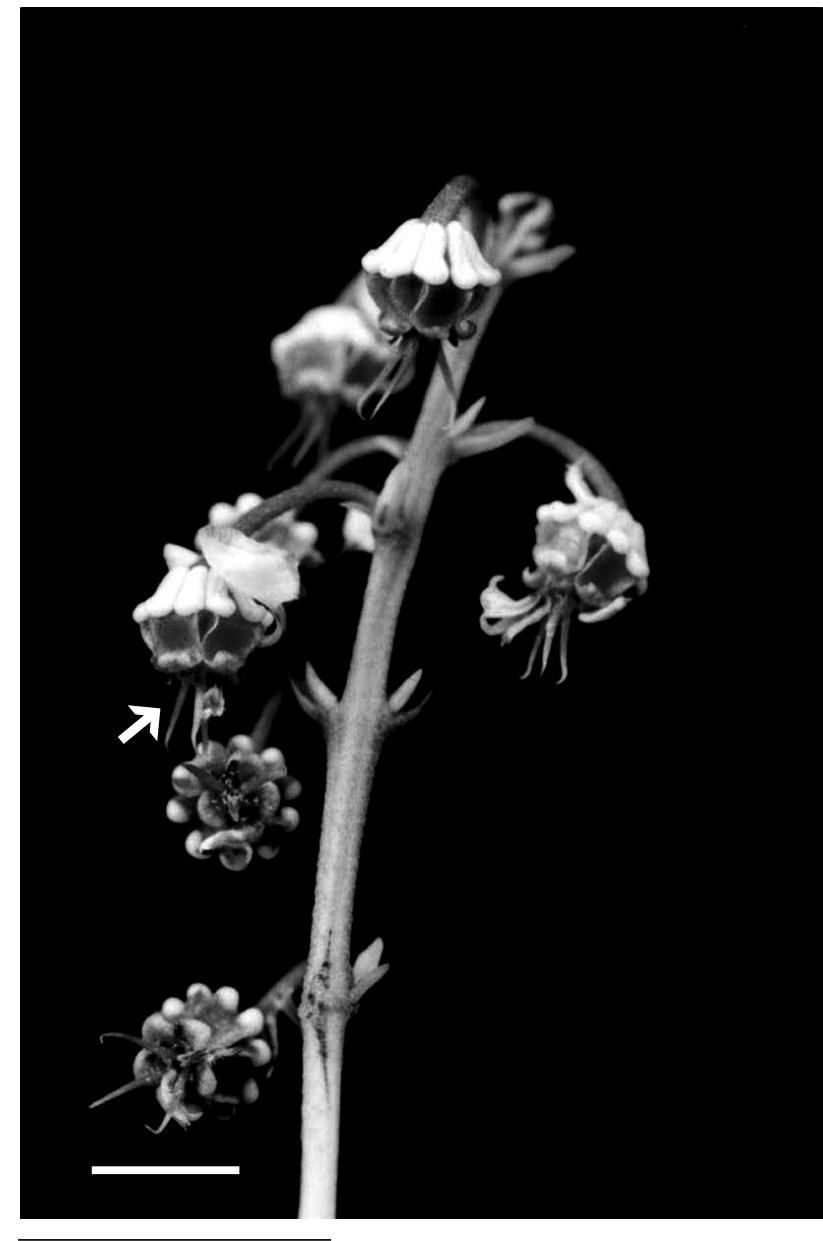

Figura 2 - racemo de $B$. coccolobifolia destacando a disposição das sépalas em torno do gineceu, após a abcisão das pétalas e estames; observar também a persistência dos estigmas nesta fase.A barra corresponde a $5,00 \mathrm{~mm}$.

garantindo a fecundação mesmo na ausência de polinizadores.

Por outro lado, os ensaios preliminares de polinização controlada mostraram que, nos indivíduos da população estudada, os estigmas dos botóes florais já se encontram receptivos desde, aproximadamente, às 24 horas precedentes ao início do processo de antese. Neste estádio as anteras ainda permanecem indeiscentes, só iniciando a liberação de pólen mais ou menos sincronicamente com o processo de abertura da flor. Tais circunstâncias denotam um comportamento protogínico da espécie e facilita o controle experimental da polinização, conforme será discutido mais adiante.

A duração total da fase de florescimento da espécie na região não foi estabelecida no presente trabalho, uma vez que não houve um acompanhamento sistemático da fenologia por um período contínuo igual ou superior a 12 meses. Para as condiçōes Distrito Federal e do Pantanal Matogrossense, a floração de B. coccolobifolia dura de dois a três meses e se concentra no início da estação chuvosa (Barros, 1992; Pott \& Pott, 1994). Em Roraima, os 
episódios de florescimento observados ocorreram no meio da estação seca, conforme o observado durante a condução do trabalho e também atestado pelos dados históricos de distribuição das chuvas no Estado (Barbosa (1997). Florescimento concentrado e/ou restrito à estação seca do ano, também foi registrado para outras espécies do gênero Byrsonima, por Barros (1992), Albuquerque \& Rêgo (1989) e Teixeira \& Machado (2000).

Adicionalmente, a ocorrência de fogo, abrangendo por completo o local de estudo, evidenciou o efeito estimulador deste fator ambiental na floração da espécie. Os racemos florais de $B$. coccolobifolia são produzidos apenas por brotações novas. Assim, a produção de novas folhas antecede a emissão de inflorescências. Indivíduos e/ou porções da copa que não apresentaram brotações novas, no primeiro episódio de florescimento registrado, permaneceram com a folhagem antiga até a ocorrência do incêndio.

No caso de B. coccolobifolia, à caducifolia acelerada e/ou induzida pelo fogo se seguiu um processo de emissão de novas brotaçōes e florescimento, visivelmente mais intenso nos indivíduos que não haviam florescido anteriormente. De acordo com Lüttge (1997), nas savanas sul-americanas há um predomínio de espécies lenhosas perenifólias, que florescem no meio ou a partir da segunda metade da estação seca. Tais espécies também apresentam diversas características de adaptação ao fogo, fator ambiental cuja ocorrência é bastante regular e antiga neste tipo de ambiente. $\mathrm{O}$ autor cita, entre outras, como exemplos típicos Curatella americana, Byrsonima verbascifolia e Palicourea rigida, plantas muito freqüentes nas savanas dos Llanos venezuelanos, assim como nas savanas roraimenses (Miranda, 1998). Portanto, B. coccolobifolia pode ser considerada uma espécie brevidecídua (Sarmiento \& Monastério, 1983; apud Oliveira, 1998), com sincronização da caducifolia, brotação e reprodução. Este comportamento garante que a dispendiosa formação de frutos seja mantida com os recursos fotossintéticos disponibilizados naquele momento, ao mesmo tempo que possibilita um ajustamento de sua produção às condições ambientais (Oliveira, 1998).

\section{INSETOS VISITANTES}

\section{Abelhas}

Durante a floração, os indivíduos de B. coccolobifolia foram visitados por abelhas das famílias Anthophoridae, gêneros Xylocopa (duas morfo-espécies) e Centris (uma morfoespécie) e Apidae (Bombus sp. e Apis mellifera). No primeiro período de observação as visitas se concentraram no intervalo das 7:00 às 14:30h. Após o fogo, o número de visitantes foi mais abundante e as visitas ocorreram durante o dia todo. Provavelmente, esta situação foi em decorrência da maior disponibilidade de flores nesta espécie e escassez visível nas demais, resultado da ação do fogo e do avanço no período estiagem.
As abelhas do gênero Xylocopa foram as mais freqüentes durante o período de observação anterior ao fogo, mostrando preferência por flores recém-abertas. Inicialmente costumam fazer vôos lentos sobre a copa da planta, em seguida pousam sobre a flor, apoiando-se em parte nas pétalas, principalmente na pétala superior, ao mesmo tempo em que esticam as pernas posteriores fazendo movimentos vibratórios sobre as anteras. Ao fazerem os movimentos vibratórios as abelhas ficam completamente empoadas de pólen e, enquanto estão debruçadas sobre as flores, seus abdomens acabam encostando-se na região estigmática. Logo depois, limpam-se esfregando as pernas anteriores nas medianas e estas, por sua vez, são limpas pelas pernas posteriores que reservam o pólen coletado. Segundo Silva (1998) e Teixeira \& Machado (2000) esses movimentos vibratórios são típicos de coletores de pólen. A troca do pólen de uma perna para a outra e seu conseqüente armazenamento, tanto pode ocorrer num pouso sobre uma folha ou mesmo em pleno vôo. Cada pouso sobre a flor costuma durar até três segundos. Na escassez de flores recém abertas, esses insetos acabam forçando os botōes florais com as mandíbulas ou, ainda, pousando sobre flores abertas com mais de um dia. Estas abelhas raramente foram vistas depois das 10:00h da manhã.

Abelhas do gênero Xylocopa são polinizadoras freqüentes de Passifloraceae (São José et al. 1991) e de Myrtaceae (Souza, 1996). Quando observadas pousando sobre as flores de B. coccolobifolia, notou-se uma acentuada desproporção entre as dimensões do visitante e das estruturas florais. Discrepância entre o diâmetro da flor e o tamanho das abelhas visitantes também foi registrada por Nara et al. (1998), em um estudo de polinização de Ouratea spruceana (Ochnaceae). Por isso, é provável que estas abelhas não sejam polinizadoras efetivas de B. coccolobifolia, mas apenas contribuam, ocasionalmente, para transferência de pólen entre plantas, favorecendo algum nível de recombinação na espécie. Adicionalmente, nenhuma das publicaçôes consultadas abordando a biologia floral de membros da família Malpighiaceae, relatou a visita de representantes deste gênero de abelhas.

Abelhas do gênero Bombus foram vistas visitando as flores, no intervalo de 7:00 às 14:30h. Seu pouso chega a durar até 3 segundos, não percorrem flores envelhecidas e a coleta de pólen é feita através de movimentos vibratórios, resultando em uma nuvem que envolve todo seu corpo. Estas abelhas também foram vistas introduzindo a probóscide entre as peças florais, provavelmente na procura de néctar. Barros (1992) observou duas espécies deste gênero de abelhas em flores de B. coccolobifolia, que foram consideradas visitantes de frequiência comum ou mediana pela autora.

Tanto as abelhas do gênero Xylocopa quanto do gênero Bombus repetem os mesmos movimentos em várias flores do mesmo indivíduo, só procurando outras plantas quando não encontram flores recém abertas ou com disponibilidade de pólen. 
Os indivíduos do gênero Centris foram freqüentes nos dois períodos de observação, com visitas concentradas no intervalo das 7:30 às 13:30h. Embora seu vôo de reconhecimento seja muito rápido, costumam ficar pousadas até sete segundos sobre a flor, debruçando-se sobre as peças florais e fazendo vibrar as anteras, que dispersam uma nuvem de pólen envolvendo seus corpos. Em seguida, limpam-se esfregando suas pernas anteriores nas posteriores, que são escovadas e armazenam o pólen coletado. Outras vezes, quando pousadas sobre a flor, suas pernas anteriores são dirigidas até as glândulas da base das sépalas e, fazendo movimentos de raspagem, coletam o óleo que logo em seguida é transferido para as pernas posteriores. Vogel (1990) destaca que o óleo produzido nos elaióforos, presentes em grande parte dos membros da família Malpighiaceae do Novo Mundo, é explorado por abelhas especializadas pertencentes à tribo Centridini da família Antophoridae. Segundo o autor, o desenvolvimento das glândulas epiteliais ou elaióforos, de um lado e das estruturas especializadas das pernas destas abelhas de outro, é decorrente de um processo co-evolutivo, iniciado após o isolamento da América do Sul do super continente Gondwana. Todos os indivíduos estudados de $B$. coccolobifolia dispóem dessas glândulas que se localizam na base de cada sépala e freqüentemente foram contactadas por estes visitantes. Abelhas do gênero Centris também foram muito freqüentes nos trabalhos realizados por Albuquerque \& Rego (1989), Barros (1992), Teixeira \& Machado (2000) e Pereira (2001), confirmando seu comportamento de coletoras de pólen e óleo, bem como o de efetivas polinizadoras de diferentes espécies de Byrsonima. Entretanto, no trabalho de Barros (1992), a frequiência de visitas de espécies de Centris em B. coccolobifolia foi considerada rara, tendo como principais visitantes membros das famílias Apidae e Halictidae, além de outros gêneros de Anthophoridae.

Apis mellifera, foi muito freqüente no segundo período de observação. Esta espécie costuma visitar várias flores da mesma planta pousando sobre e percorrendo as estruturas reprodutivas, o que as deixa encobertas de pólen que é, posteriormente, retirado e transferido das pernas anteriores para as posteriores e armazenado nas corbículas. O período de visitas estende-se desde 7:30 até 16:00h e costuma durar até cinco segundos em cada flor. Durante o pouso, as abelhas aproveitam a oportunidade para introduzir a probóscide na base das estruturas florais à procura de néctar. Embora seja uma espécie exótica de introdução recente no continente Americano e, portanto, sem qualquer estrutura especializada que permita a exploração do recurso floral disponibilizado nos elaióforos, estas abelhas apresentam comportamento invasor e são eficientes coletoras de pólen. Silva (1998), ao fazer a análise do mel produzido por A. mellifera, encontrou, por várias vezes, grãos de pólen de espécies do gênero Byrsonima. Frisch (1957) e Barth (1985) (apud Silva, 1998) ressaltam que muitas vezes o pólen poderá ser um subproduto em busca do néctar, e quando as abelhas visitam outras flores o pólen que está aderido às suas pernas acabam contactando o estigma da flor visitada, o que poderá promover a polinização cruzada.

No trabalho de Barros (1992), Apis mellifera foi considerada visitante comum ou abundante em flores de $B$. coccolobifolia e de outras quatro espécies de Byrsonima estudadas pela autora. Entretanto, trabalhos envolvendo a biologia floral de $B$. crassifolia (Rêgo \& Albuquerque, 1989) e B. sericea (Teixeira \& Machado, 2000) não registraram a ocorrência de visitas desta espécie de abelhas.

As flores de B. coccolobifolia apresentam atributos típicos de síndrome de melitofilia (sensu Faegri \& Pijl, 1979), como zigomorfia, antese diurna e recompensas florais como pólen e óleo. Entretanto, a autopolinização espontânea ou automática, conforme discutido a seguir, também deve ocorrer com freqüência, tendo em vista a eficiência reprodutiva apresentada pela espécie, quando comparada com a baixa freqüência de visitantes florais observada.

\section{OUTROS INSETOS VISITANTES}

Coleópteros da família Tenebrionidae, foram observados percorrendo o racemo em busca das flores que estão liberando óleo, durante a noite, ficando por horas na base das glândulas, sendo considerados como pilhadores. Camponotus sp. são formigas que tem o hábito noturno e constantemente percorrem todo o racemo floral. Estas formigas parecem manter uma estreita relação ecológica com a planta, tendo em vista que ao se tocar o racemo as mesmas respondem com ataque.

Os frutos de B. coccolobifolia são muito predados por Polistinaesp. (Vespidae), que chegam a ficar até cinco minutos perfurando-os. As vespas costumam visitar os frutos no final da tarde, quando a freqüência de outros visitantes é menor. Espécies da família Formicidae costumam freqüentar constantemente os racemos, muitas chegam acompanhar a flor desde botão floral até a senescência. Também foi observada predação de frutos por hemípteros do gênero Leptoglossus, através da sucção da seiva tanto de frutos verdes quanto maduros.

\section{SISTEMA REPRODUTIVO}

Os resultados dos experimentos de determinação do sistema reprodutivo de B. coccolobifolia são apresentados nas tabelas $1 \mathrm{e}$ 2. Em todos os tratamentos foram produzidos frutos, à exceção do tratamento de apomixia. Embora tenha ocorrido a formação de dois frutos em um total de 75 observaçôes, no tratamento "apomixia I" (tabela 2), atribuiu-se estes resultados à contaminação polínica do material manipulado e considerou-se que esta espécie não produz frutos apomíticos.

Os dados do primeiro experimento, apresentados na tabela 1 , mostram que os tratamentos de xenogamia, com e sem emasculação, produziram maior quantidade de frutos, não diferindo entre si (percentual combinado de $63,3 \%$ de frutos 
formados) e diferindo significativamente dos demais tratamentos. A polinização natural e a geitonogamia apresentaram percentuais de frutificação iguais a $41,15 \%$ e $40 \%$, respectivamente, diferindo significativamente dos resultados de autopolinização espontânea (13,8\%).

Os resultados do segundo experimento, apresentados na tabela 2, de certo modo concordam com os do experimento anterior, ou seja, o maior percentual de frutificação ocorreu no tratamento de xenogamia $(65,6 \%)$, que novamente diferiu significativamente dos demais. Entretanto a autopolinização espontânea apresentou maior quantidade de frutos formados $(44,0 \%)$ quando comparada com dados do primeiro experimento, não diferindo da polinização natural $(46,1 \%)$ e sendo significativamente superior a geitonogamia $(31,4 \%)$. Os tratamentos de autopolinizações induzidas I e II não diferiram entre si (32,3\% e 33,3\%, respectivamente) e nem dos demais tratamentos, à exceção da xenogamia e da polinização natural (para o tratamento de autopolinização induzida I).

A razão da grande discrepância observada nas frutificações por autopolinização espontânea, entre os dois experimentos não pôde ser estabelecida. Entre as possíveis causas, destacam-se um possível erro de amostragem e/ou o favorecimento do processo de geitonogamia, ao nível de inflorescências isoladas, decorrente da antese em horários variados do dia, que foi observada apenas durante a execução do segundo experimento. Barros (1992) trabalhando com uma população desta espécie no Distrito Federal, obteve percentuais de frutificação iguais a 33,7 $(n=77)$ para polinização natural, $10,5(\mathrm{n}=19)$ para autopolinização espontânea e 8,9 (n=78), para autopolinização manual, resultados compatíveis com os obtidos no primeiro experimento deste trabalho, à exceção da autopolinização manual.

De acordo com os dados apresentados, B. coccolobifolia é uma espécie autocompatível, com a maioria dos tratamentos envolvendo autogamia apresentando percentuais de frutificação semelhantes aos verificados na polinização espontânea. Estes resultados diferem daqueles encontrados para outras espécies do gênero Byrsonima, como os de Rêgo \& Albuquerque (1989), que verificaram que $B$. crassifolia é uma espécie com autoincompatibilidade, manifestada tanto pelo abortamento da maioria das flores autofecundadas, quanto de todos os frutos que iniciaram o desenvolvimento. Auto-incompatibilidade completa foi também observada por Teixeira \& Machado (2000) ao avaliarem o sistema reprodutivo de B. sericea. Por outro lado, Silva (1990) obteve sucesso em autopolinizaçóes manuais desta espécie. Barros (1992) estudou a biologia reprodutiva de sete espécies simpátricas do gênero Byrsonima e considerou que elas apresentavam "certo grau de autocompatibilidade", com percentuais de frutificação por autopolinização variando entre $5,2 \%$ a $16,3 \%$. Outro estudo realizado por Sigrist \& Sazima (2004), com 12 espécies de Malpighiaceae dos gêneros Banisteriopsis, Dicella, Mascagnia, Stigmaphyllon e Tetrapterys,

Tabela 1 - Frutificação e valores de qui-quadrado para testes de comparação dos tratamentos de avaliação do sistema reprodutivo de Byrsonima coccolobifolia, experimento I.

\begin{tabular}{|c|c|c|c|c|c|}
\hline Tratamento & $\begin{array}{l}\text { Sucesso }(\%)\left(\mathrm{N}^{0} \mathrm{de}\right. \\
\text { Frutos/ } \mathrm{N}^{0} \text { de Flores) }\end{array}$ & $\begin{array}{l}\text { Xenogamia s/ } \\
\text { Emasculação }\end{array}$ & $\begin{array}{l}\text { Xenogamia c/ } \\
\text { Emasculação }\end{array}$ & Autopolinização Espontânea & Polinização Natural \\
\hline Xenogamia s/ Emasculação & $63,21(67 / 106)$ & - & - & - & - \\
\hline Xenogamia c/ Emasculação & $64,00(64 / 100)$ & $0,04^{\text {ns }}$ & - & - & - \\
\hline Autopolinização Espontânea & $13,79(16 / 116)$ & $66,23^{\star \star}$ & $58,03^{\star *}$ & - & - \\
\hline Polinização Natural & $41,15(100 / 243)$ & $14,36^{\star *}$ & 14,80 ** & $65,23^{\star *}$ & - \\
\hline Geitonogamia & $40,00(40 / 100)$ & 11,24 ** & $11,54^{* *}$ & 13,09 ** & $0,03^{\text {ns }}$ \\
\hline
\end{tabular}

** Diferença significativa a $1 \%$ de probabilidade

ns Diferença não significativa

Tabela 2 - Frutificação e valores de qui-quadrados para testes de comparação dos tratamentos de avaliação do sistema reprodutivo de Byrsonima coccolobifolia, experimento II.

\begin{tabular}{|c|c|c|c|c|c|c|}
\hline Tratamento & $\begin{array}{l}\text { Sucesso }(\%)\left(\mathrm{N}^{0} \text { de }\right. \\
\text { Frutos } / \mathrm{N}^{0} \text { de Flores) }\end{array}$ & $\begin{array}{l}\text { Xenogamia s/ } \\
\text { Emasculação }\end{array}$ & $\begin{array}{l}\text { Autopolinização } \\
\text { Espontânea }\end{array}$ & $\begin{array}{l}\text { Autopolinização } \\
\text { Induzida I }\end{array}$ & $\begin{array}{l}\text { Autopolinização } \\
\text { Induzida II }\end{array}$ & $\begin{array}{l}\text { Polinização } \\
\text { Natural }\end{array}$ \\
\hline Xenogamia s/ Emasculação & $65,60(59 / 90)$ & - & - & - & - & - \\
\hline Autopolinização Espontânea & $44,00(66 / 150)$ & $8,65^{\star \star}$ & - & - & - & - \\
\hline Autopolinização Induzida I & $32,26(30 / 93)$ & 25,74 ** & $3,31 \mathrm{~ns}$ & - & - & - \\
\hline Autopolinização Induzida II & $33,33(25 / 75)$ & $16,98^{* *}$ & $2,36 n s$ & 0,73 ns & - & - \\
\hline Polinização Natural & $46,06(76 / 165)$ & $8,87^{\star *}$ & $0,12 \mathrm{~ns}$ & $4,67^{*}$ & $3,42 \mathrm{~ns}$ & \\
\hline Geitonogamia & $31,43(33 / 105)$ & $16,34^{\star \star}$ & $4,11^{*}$ & $0,14 \mathrm{~ns}$ & $0,07 \mathrm{~ns}$ & $5,71^{\star}$ \\
\hline Apomixia I & $2,67(02 / 75)$ & - & - & - & - & - \\
\hline Apomixia II & $00,00(00 / 90)$ & - & - & - & - & - \\
\hline
\end{tabular}

** $e$ * Diferença significativa a $1 \%$ e $5 \%$ de probabilidade, respectivamente

ns Diferença não significativa 
evidenciou a existência de diferentes comportamentos reprodutivos, com algumas espécies sendo autoincompatíveis, outras autocompatíveis e uma agamospérmica ou apomítica. $\mathrm{O}$ nível de autogamia espontânea das espécies autocompatíveis, entretanto, foi considerado desprezível pelas autoras.

O índice de autoincompatibilidade (ISI), que mede a relação entre o percentual de frutificação por autopolinização e o percentual de frutificação por polinização cruzada, foi de 0,22 no primeiro experimento e 0,50 no segundo, considerando a autopolinização espontânea, ou 0,67 , considerando os valores combinados de autopolinização induzida. Os resultados da eficiência reprodutiva (RE), por outro lado, foram semelhantes nos dois experimentos, com índices iguais a 64,7\% e 70,3\%, respectivamente. Este índice mede a razão entre o percentual de frutos formados por polinização espontânea e o percentual de frutificaçāo por polinização cruzada manual.

De acordo com o critério adotado por Oliveira \& Gibbs (2000), um de ISE de 0,22 indica que B. coccolobifolia é uma espécie autoincompatível (ISI $<0,25)$, enquanto os outros dois valores obtidos atestam a autocompatibilidade. Utilizando os dados de polinização fornecidos por Barros (1992), Oliveira \& Gibbs (2000) classificaram B. coccolobilofia como autoincompatível ( $\mathrm{ISE}=0,26$ ). Entretanto, conforme esclarecem os autores, neste caso específico, o ISE foi estimado através da razão entre o percentual de frutos formados por autopolinização e o percentual de frutos formados por polinização natural. Se este critério fosse utilizado no cálculo do ISE no presente trabalho, os valares obtidos seriam 0,34 e 0,71 , respectivamente, mais uma vez reforçando o caráter autocompatível da espécie. Por outro lado, a diferença altamente significativa dos tratamentos de xenogamia atestam a vantagem deste tipo de acasalamento em relação a todos os demais, indicando que algum tipo de mecanismo que favorece a polinização cruzada também deve estar operando na reprodução da população.

Portanto, parece que Byrsonima coccolobifolia apresenta um sistema reprodutivo misto com níveis elevados de alogamia e autogamia. Tal sistema, segundo Scariot et. al. (1991), combina as vantagens da autofecundação e polinização cruzada, garantindo um alto nível de adaptabilidade da população às condiçōes vigentes do ambiente associado à manutenção de elevado potencial evolutivo através da recombinação, o que capacita a espécie para a colonização de novas e extensas áreas.

\section{AGRADECIMENTOS}

A Dr ${ }^{a}$ Joana D'arc Ribeiro (INPA), por ter contribuído na identificação parcial dos insetos.

Ao Pesquisador Joaci Freitas Luz - EMBRAPA-RR pela colaboração no registro fotográfico.

Ao Dr. Reinaldo Imbrózio Barbosa (INPA) e Celice Alexandre
Silva (doutoranda em botânica - UFV), pela revisão crítica do texto.

\section{BIBLIOGRAFIA CITADA}

Albuquerque, P.M.C.; Rêgo, M.M.C. 1989. Fenologia das abelhas visitantes de murici (Byrsonima crassifolia Malpighiaceae). Boletim do Museu Paraense Emilio Goeldi, Série Zooloógica, 5(2): 63-178.

Alves, T. M.; Silva, F.A.; Brandão, M. et al. 2000. Biological screening of brazilian medicinal plants. Memórias do Instituto Oswaldo Cruz, 95 (3): 367-373.

Barbosa, R.I. 1997. Distribuição das chuvas em Roraima. In: Barbosa, R.I.; Ferreira, E. J. G.; Castelón, E. G. (eds.) Homem, ambiente e ecologia no Estado de Roraima. Instituto Nacional de Pesquisas da Amazônia, Manaus, Amazonas. p. 325-335.

Barros, M.A.G. 1992. Fenologia da floração, estratégias reprodutivas e polinização de espécies simpátricas do gênero Byrsonima Rich (Malpighiaceae). Revista Brasileira de Biologia, 52(2): 343-353.

Barroso, G.M.; Peixoto, A.L.; Ichaso, C.L.F.; Costa, C.G.; Guimarães, E.F.; Lima, H.C. 1991. Sistemática de angiospermas do Brasil. Vol. 2. Editora UFV, Viçosa, Minas Gerais, p.325329.

Bergamin, M. 1998. Aspectos reprodutivos e distribuição de duas espécies de Byrsonima (Malpighiaceae) em área de cerradão na Reserva Biológica de Mogi Guaçu, SP. Dissertação de mestrado, Instituto de Biociências de Rio Claro/ Unesp - Rio Claro, São Paulo. 73pp.

Bullock, S.H. 1985. Breeding systems in the flora of a tropical deciduous forest. Biotropica 17(4): 287-301.

Cavalcante, P. B. 1991. Frutas comestiveis da Amazônia, $5^{\text {a }}$ ed. Museu Paraense Emílio Goeldi, Belém 190 pp.

EMBRAPA (Empresa Brasileira de Pesquisa Agropecuária). 1982. Relatório técnico anual da Unidade de Execução de Pesquisa de Âmbito Territorial - UEPAT Boa Vista. UEPAT, Boa Vista, Roraima. 212pp.

Faegri, K. van der Pijl, L. 1976. The Principles of pollination ecology. $2^{\text {nd }}$ ed. Pergamon Press, Oxford, U.K. 291pp.

Freitas, C.V.; Oliveira, P.E. 2002. Biologia reprodutiva de Copaifera langsdorffii Desf. (Leguminosae, Caesalpinioideae). Revista Brasileira de Botânica. 25(3): 311-321.

Gribel, R. 2001. Biologia reprodutiva de plantas amazônicas: importância para o uso, o manejo e a conservação dos recursos naturais. Humanidades - Biologia. 48: 111-117.

Lüttge, U. 1997. Physiological ecology of tropical plants. SpringerVerlag, Berlin. 384 pp.

Miranda, I.S. 1998. Flora, fisionomia e estrutura das savanas de Roraima, Brasil. Tese de Doutorado. Instituto Nacional de Pesquisas da Amazônia / Universidade Federal do Amazonas, Manaus, Amazonas. 186 pp.

Miranda, I.S.; Absy, L.M. 1997. Flora fanerogâmica das savanas de Roraima. In: Barbosa, R I.; Ferreira, E. J. G.; Castelón, E. G. (Eds.). Homem, Ambiente e Ecologia no Estado de Roraima. Instituto Nacional de Pesquisas da Amazônia, Manaus, Amazonas, p.445-455. 
Missouri Botanical Garden. 2002. Specimen Data Base. Disponível em: http://mobot 1. mobot.org/website. Acesso em 14 abril 2002.

Nara, A. K.; Júnior, M. A. de A. ; Braga, P. I. S. 1998. Aspectos da polinização de Ouratea spruceana Engl. (Ochnaceae) ocorrente na Reserva Biológica de Campina-INPA. Boletim do Museu Integrado de Roraima, B. V. 4: 11-22.

Newstrom, L.E.; Frankie, G.W.; Baker, H.G. 1994. A new classification for plant phenology based on flowering patterns in lowland tropical rain forest trees at La Selva, Costa Rica. Biotropica 26(2): 141-159.

Oliveira, P.E. 1998. Fenologia e biologia reprodutiva das espécies de cerrado. In: Sano, S.M.; Almeida, S.P. (Eds.). Cerrado: ambiente e flora. Embrapa, Planaltina, Distrito Federal. p.169-188.

Oliveira, P.E.; Gibbs, P.E. 2000. Reprodutive biology of wood plants in cerrado community of Central Brazil. Flora 195:311329.

Pereira, J.O.P. 2001. O papel das abelhas do gênero Centris na polinização e sucesso reprodutivo do muricizeiro (Byrsonima crassifolia L.). Dissertação de mestrado, Universidade Federal do Ceará, Fortaleza, Ceará. 59pp.

Pott, A.; Pott, V.J. 1994. Plantas do Pantanal. Empresa Brasileira de Pesquisa Agropecuária, Corumbá, Mato Grosso. p. 187-193.

Rêgo, M.M.C.; Albuquerque, P.M.C. 1989. Comportamento de abelhas visitantes do murici, Byrsonima crassifolia (L.) Kunth. Malpighiaceae. Boletim do Museu Paraense Emílio Goeldi, Série Zoológica 5(2): 179-193.

São José, A. R.; Ferreira, S.R.; VAZ, R. L. 1991. A cultura do maracujá no Brasil. FUNEP, Jaboticabal, São Paulo. 247pp.

Scariot, A. O.; Lleras, E.; Hay, J. D. 1991. Reproductive Biology of the Palm Acrocomia aculeata in Central Brazil. Biotropica. 23(1): 12-22.

Sigrist, M.R.; Sazima, M. 2004. Pollination and reproductive biology of twelve species of neotropical Malpighiaceae: stigma morphology and its implications for breeding system. Annals of Botany, 94:33-41.
Silva, S. da. 1998. Recursos Tróficos de Abelhas Apis mellifera L. (Hymenoptera, Apidae) em uma área de Savana do Estados de Roraima: fontes de néctar e pólen. Dissertação de Mestrado, Instituto Nacional de Pesquisas da Amazônia / Universidade do Amazonas, Manaus, Amazonas. 88pp.

Silva, S.I. 1990. Floração e frutificação de duas variedades de Byrsonima sericea $D C$. Dissertação de Mestrado, Universidade Federal Rural de Pernambuco, Recife, Pernambuco. 93pp.

Souza, M. A. D. 1996. Biologia reprodutiva de onze espécies de Myrtaceae em floresta de terra firme na Amazônia Central. Dissertação de mestrado, Instituto Nacional de Pesquisas da Amazônia / Universidade do Amazonas, Manaus, Amazonas.75pp.

Teixeira, L.A.G.; Machado I.C. 2000. Sistema de polinização e reprodução de Byrsonima sericea DC (Malpighiaceae). Acta Botanica Brasilica. 14(3): 347-357.

Veloso, H.P.; Góes Filho, L.; Leite, P.F.; Silva S.B.; Ferreira, H.C.; Loureiro, R.L.Terezo, E.F.M. 1975. IV Vegetação: As regiōes fitoecológicas, sua natureza e seus recursos econômicos - estudo fitogeográfico. In: BRASIL. Ministério das Minas e Energia, Departamento Nacional de Produção Mineral. Projeto RADAMBRASIL. Folha, NA. 20 Boa Vista e parte das Folhas NA. 21 Tumucumaque, NB. 20 Roraima e NB. 21. Rio de Janeiro, DNPM, Projeto RADAMBRASIL.

Vogel, S. 1990. History of the Malpighiaceae in the light of pollination ecology. Memoirs of the New York Botanical Garden. 55: 130-142.

Zapata, T.R.; Arroyo, M.T.K. 1978. Plant reproductive ecology of a secundary deciduous tropical forest in Venezuela. Biotropica 10(3): 221-230.

Recebido em 11/11/2003

Aceito em 11/04/2006 